\title{
AOR
}

Selected Papers of \#AoIR2020:

The $21^{\text {st }}$ Annual Conference of the

Association of Internet Researchers

Virtual Event / 27-31 October 2020

\section{COPYRIGHT GOSSIP: EXPLORING COPYRIGHT KNOWLEDGE, SENTIMENT, AND BLACKBOX THEORIES ON YOUTUBE}

\author{
D. Bondy Valdovinos Kaye \\ Queensland University of Technology \\ Joanne E. Gray \\ Queensland University of Technology
}

\section{Introduction}

This study investigates copyright discourses on YouTube. Through a qualitative content analysis of approximately 200 YouTube videos, we explore how YouTube creators understand copyright law, and how they navigate a highly technical and dynamic copyright enforcement ecosystem. Our findings offer insights into how digitally situated cultural producers are impacted by and respond to automated content moderation. This is important because increasingly lawmakers around the world are asking digital platforms to implement efficient systems for content moderation (Reda, 2019) and yet there is a lack of good information about the stakeholders most directly impacted by these practices. In this study, we provide a systematic analysis of the opinions and strategies of creators who are affected by YouTube's copyright enforcement measures.

\section{Background and Literature Review}

For cultural producers, copyright offers both benefits and harms. Copyright provides authors of original works exclusive rights to their work, which facilitates commodification and market exchange (Ginsburg, 2015). Yet, overly restrictive copyright laws that prevent access to existing resources can also prevent authors from creating and disseminating new work (Lessig, 2008). In digital media and communication environments, this tension often plays out as a battle between larger established creative industries entities--such as major record labels, movie studios and broadcasters--and smaller independent producers who are native to digital creation and dissemination ecosystems (Cunningham \& Flew, 2019). As one of the largest and most widely-used platforms for content creation and dissemination globally (YouTube, 2020),

Suggested Citation (APA): Kaye, D.B.V. \& Gray, J.E. (2020, October). Copyright gossip: Exploring copyright knowledge, sentiment, and blackbox theories on YouTube. Paper title. Paper presented at AolR 2020: The $21^{\text {th }}$ Annual Conference of the Association of Internet Researchers. Virtual Event: AolR.

Retrieved from http://spir.aoir.org. 
YouTube is a prominent staging ground for contests between large entertainment industry copyright owners and independent producers.

In digital spaces, copyright enforcement is governed in significant part by the private copyright rule-making and enforcement policies of internet platforms (Bridy, 2016; Gray, 2020). On YouTube, copyright owners who participate in YouTube's rights management programs have available to them a wide and constantly evolving array of tools they can use to contest or remove unlicensed content posted by users to YouTube (Urban et al., 2016). These enforcement measures are justified as in the interest of creators, by protecting their economic rights to remuneration and financial exploitation and their moral rights to attribution and integrity (Edwards et al., 2015a). For many YouTube creators, however, the risk of having a video de-monetised or removed from YouTube due to a copyright claim is relatively high (Gray \& Suzor, 2020). YouTubers are required to interact with a complex copyright enforcement system that is highly automated, dynamic, and opaque (Maayan Perel \& Niva Elkin-Koren, 2017). Often, when doing so, YouTubers participate in copyright discourses, posting videos sharing their experiences with copyright enforcement. In many of these videos, they offer interpretations of copyright law and explanations of YouTube's technical systems, and they offer strategies for avoiding copyright strikes or removals. In doing so, these creators directly contribute to discourses surrounding copyright policies and practices that are championed as serving their best interests.

Research by Sophie Bishop (2019) shows how YouTube creators participate in algorithmic gossip, that is, socially informed theories, strategies, and advice, to help navigate YouTube's recommendation algorithms and how this information can shape production practices on the platform (Bishop, 2020). Previous research has also examined the degree to which rightsholders and rights users engage in and shape copyright law and policy debates in the UK (Edwards et al., 2015). Other research has shown how independent, amateur, or other smaller-scale creators often do not have accurate knowledge of copyright law or lack understanding of why they have been penalised (Pappalardo et al., 2017; Phillips \& Street, 2015). These studies did not, however, closely examine the particular copyright knowledge and experiences of YouTube creators. By studying public communications about copyright enforcement made by YouTube creators, we can improve understanding of the impact of automated, opaque and dynamic digital copyright enforcement systems on cultural producers operating in digital media and communication environments.

\section{Methodology}

For this study, between November and December 2019, we manually collected a sample of 200 YouTube videos using keyword search terms "Copyright" "Copyright Strike" "Copyright Claim" and "DMCA". Videos were excluded from analysis if they were non-English language videos and if they were published by a formal institute such as a government or educational organisation. For each video, we logged the video publication date, URL, title, account, channel, hashtags, and number of views, likes, comments, and subscribers. We conducted a pilot study of 20 randomly selected videos, analysing each video in order to develop a codebook. The codebook ultimately included categories for coding sentiment towards copyright law generally and copyright enforcement on YouTube specifically; the accuracy of legal knowledge proffered by 
YouTubers; theories of how algorithmic enforcement on YouTube works; and strategies for avoiding a copyright claim, block or demonetisation.

\section{Initial Results}

Our initial analysis suggests that professional YouTubers have a relatively sophisticated knowledge of copyright law and of YouTube's copyright enforcement system, in contrast to creators from more traditional creative industries sectors, such as music, filmmaking and visual art (Pappalardo et al., 2017; Phillips \& Street, 2015). They demonstrate a largely accurate knowledge of issues such as copyright subsistence, copyright exceptions, and permission and remuneration requirements. Initial results also suggest a highly negative sentiment towards YouTube's copyright enforcement system is shared among YouTube creators, with creators frequently expressing frustration that the system is unfair, broken and biased towards the interests of large media and entertainment corporations. Overall, our preliminary analysis suggests YouTube's copyright enforcement system represents an outsized force on YouTube, influencing the creative practice of YouTubers, and, by participating in copyright discourses, YouTube creators, unlike their offline counterparts, have become highly adept at navigating copyright law enforcement.

\section{References}

Bridy, A. (2016). Copyright's Digital Deputies: DMCA-plus Enforcement by Internet Intermediaries. In J. Rothchild (Ed.), Research Handbook on Electronic Commerce Law: Vol. Edward Elgar.

Cunningham, S., \& Flew, T. (2019). A Research Agenda for Creative Industries. Edward Elgar Publishing.

Edwards, L., Klein, B., Lee, D., Moss, G., \& Philip, F. (2015). Discourse, justification and critique: Towards a legitimate digital copyright regime? International Journal of Cultural Policy, 21(1), 60-77. https://doi.org/10.1080/10286632.2013.874421

Ginsburg, J. (2015). The Author's Place in the Future of Copyright. The Centre for Law and Economic Studies Columbia University School of Law, Working Paper No. $512,1$.

Gray, J. E. (2020). Google Rules: The History and Future of Copyright Under the Influence of Google. Oxford University Press.

Gray, J., \& Suzor, N. (2020). Playing with Machines: Using machine learning to understand automated copyright enforcement at scale. Big Data \& Society, Forthcoming.

Lessig, L. (2008). Remix. Penguin Press.

Maayan Perel \& Niva Elkin-Koren. (2017). Black Box Tinkering: Beyond Transparency in Algorithmic Enforcement. Florida Law Review. 
Pappalardo, K., Aufderheide, P., Stevens, J., \& Suzor, N. (2017). Imagination foregone: A qualitative study of the reuse practices of Australian creators. QUT.

Phillips, T., \& Street, J. (2015). Copyright and musicians at the digital margins. Media, Culture \& Society, 37(3), 342-358. https://doi.org/10.1177/0163443714567018

Reda, J. (2019, January 2). Upload filters. Julia Reda. https://juliareda.eu/eu-copyrightreform/censorship-machines/

Urban, J. M., Karaganis, J., \& Schofield, B. L. (2016). Notice and Takedown in Everyday Practice. UC Berkeley Public Law Research Paper 2755628. 